\title{
APPLICATION OF CONJUGATE SIMULATION FOR DETERMINATION OF TEMPERATURE AND STRESS DISTRIBUTIONS DURING CURING PROCESS OF PRE-IMPREGNATED COMPOSITE FIBERS
}

\begin{abstract}
The composites made of continuous fibers in the form of unidirectional and fabric prepregs are widely used in many fields of engineering for the production of lightweight and durable parts or whole structures. To achieve this, we not only need to possess knowledge of the composite mechanics, but also have to master the technology. In most cases, particularly for parts with advanced geometric shapes, autoclaving technique is used. The success of the carried out process occurs when the prepreg reaches the proper temperature throughout its volume in the specified time, where there are no overheated or unheated zones as well as when the prepreg is correctly pressed against the mold. In order to ensure adequate stiffness, the mold has much greater thickness than formed composite and the stiffening ribs. The result is that the time required for prepreg heating is greatly extended. To prevent this, the appropriate electric heaters embedded in the silicone grips are used.

The paper presents problems related to the mold structures and application of numerical methods aiming at early verification of the temperature and stress distribution. The coupled analysis of CFD (computational fluid dynamic) and heat transfer structural simulations were performed in Abaqus program. The studies were carried out for the airfoil fragment. A total of 12 simulations were conducted, 6 cases in which heat was supplied only from air flowing through the autoclave and 6 cases which included heaters inside the silicone grips. In the result the inhomogeneity of prepreg heating for each of the mold geometry was compared, and the average temperature was obtained after 60 seconds from the process initiation. Both the pressure inside the silicone grips (before inserting the mold into the autoclave) and the non-uniform temperature distribution result in the formation of stresses whose values were analyzed for molds made of aluminum. For this purpose the temperature dependent elastic - plastic material model was used for aluminum molds.
\end{abstract}

Keywords: CFD simulation, co-simulation, mould

\section{Introduction}

Manufacturing of products made of fiber composites with prepregs is very complicated. Curing process of a polymer matrix takes place in a strictly defined temperature, which should be uniform in the entire volume of composite structural elements. When the element shape is complicated e.g. an airfoil, it is necessary to use a mold with variable thickness. It is due to nonuniform heating, when autoclave or an oven are used. This requires an additional heat supply from specially distributed internal heating elements. These problems were analysed in several papers:

- The authors in [1] proposed replacement of the autoclaving process by thermal process curing (TPC). They compared products obtained by both techniques and they did not notice differences in their quality. The TPC method is more economical, because heat delivery comes from the electric heaters, which are close to prepreg surface. However, application of the TPC method is limited only to simple, open surface structural elements.
- A new electromagnetic induction method for heating during curing processes was proposed in [2]. This method is mainly used for making connections of metal - composite or composite - composite. However, non - magnetic materials require additional susceptors which can transform electromagnetic energy into heat.

- Heating in the autoclave [1] has disadvantage as the cure cycle can last up to 24 hours. Therefore in [3] a method of supplying heat by microwaves was proposed. In spite of advantages it is not a widely used method both in industry and research centers. The paper presents the use of microwave heating for carbon - epoxy prepregs. Investigations were conducted for flat samples subjected to curing by microwave and oven. Obtained results in mechanical tests lead to conclusion that the Young's modulus and tensile strength have similar values in comparison to heating in the autoclave, but for samples cured by microwave a significantly higher compressive strength was achieved. POLAND 
- Discussion how to get uniformity of the curing process was reported in [4] by numerical example of 3D simulations taking into account heat from the exothermic curing reactions and Carbon Fiber Reinforced Plastics (CFRP) mold heating. In order to model heat transfer from the curing plate to environment during curing a convection coefficient of 21 $\mathrm{W} / \mathrm{mK}$ was used. However, in the numerical analysis very simple laminate plate of thickness $30 \mathrm{~mm}$ was modeled. The whole technological process consisted of 3 steps: heating up, exothermic reaction, cooling down and hold.

- The role of tools in composite production process was emphasized in [5]. The tools for providing geometry of elements also serve to consolidation and help in heat transfer to polymer matrix of the composite. The authors distinguish 6 different parameters affecting the heated tools with fluid flow: channel geometry, channel profiles, channel layout, material type, fluid type, flow mode. The aim of the paper was selection of the most important parameters to achieve the most uniform temperature in the shortest time. To choose the optimal solution the Taguchi method was used. Thickness of the tool should be as small as possible to ease heat transfer, but thick enough to withstand the internal pressure. In conclusion, it was found that the channel cross-section has little effect on temperature distribution. The most important parameter is the channel routing.

- The papers [6,7] concerned heating of tools by oil for laminar and turbulent flow. The authors analysed influence of a flow rate effect on: (1) temperature distributions along the channels and (2) temperature inside the tool. The advantage of this solution is that the oil can also serve as a cooling medium of the tool after the process. The temperature distribution affects not only the curing process of composite product, but also contributes to the level of internal stresses in the mold. However, the analysis was limited to the heat tool with a simple flat surface. The laminar flow (for $R e<2300$ ) results in uniform heating of the tool, but the process is long and takes about 2 hours. For $R e>10000$ we have turbulent flow and inhomogeneous temperature distribution, which arises during the first few minutes, but the tool heats up much faster.

- According to [8] the proper design and construction of mold is the most crucial step in manufacturing of new composite products. The numerical analysis concerned production of composite element with the omega cross-sections was done with use of electric heating. Both a Liquid Composite Holding Method (LCHM) and the autoclaving technique have disadvantages, i.e.: (1) inefficient heavy and expensive forms, (2) intensive energy processing. Therefore other methods should be proposed with processing outside the autoclave. One option is designing the mold as a sandwich structure, getting in this way homogeneous temperature distribution in the tool.

In conclusion, composite production is a difficult process, because it is necessary to guarantee appropriate temperature distribution, e.g. [9]. To prevent manufacturing of defective products an initial analysis of the mold heating and stress analysis are needed. Conjugate Fluid Dynamics (CFD) simulations [10-12] are commonly used in many engineering fields where flows occur and can also be used to determine the temperature distribution during the mold heating in an autoclave. This is particularly important when the shape of the tools has a changeable geometry.

Therefore, in this paper, we proposed a new method with application of the CDF to describe:

- $\quad$ heating process of the mold with complex shape by air flowing

- behavior of the additional internal heating of the tool by system of channels to get a more uniform temperature distribution.

By using the CFD method, the time after which the mold reaches the required temperature can be also determined.

\section{The tools with internal heating}

The tools with internal heating [9] have embedded special heating elements inside. One can distinguish hard and soft heating systems of temperature equalization. In the hard system of temperature equalization a small distance between the heating elements and the prepreg surface is introduced, what results in large temperature fluctuations. During production of extremely precise structural parts to achieve stability of the final dimensions and good mechanical properties of the product, the uniform heating is required in the process. Thus the soft system of mold temperature equalization is much better. The greater distance from the prepreg surface to heating wires and smaller spacing between them are assumed. In this case we get less intensive heat transfer, but the temperature uniformity will be much higher. The use of tools with internal heating elements often affect improvement of the products quality. This applies particularly to products with large dimensions and having complex shapes. It is very difficult to create uniform heating and cooling molds of such products in dryers, because their size and shape disrupt continuous air flow and temperature distribution. Electric heating elements can be used for tools of any complex shape. Another advantage of this approach is the ability to calculate accurately the required heat power depending on the desired

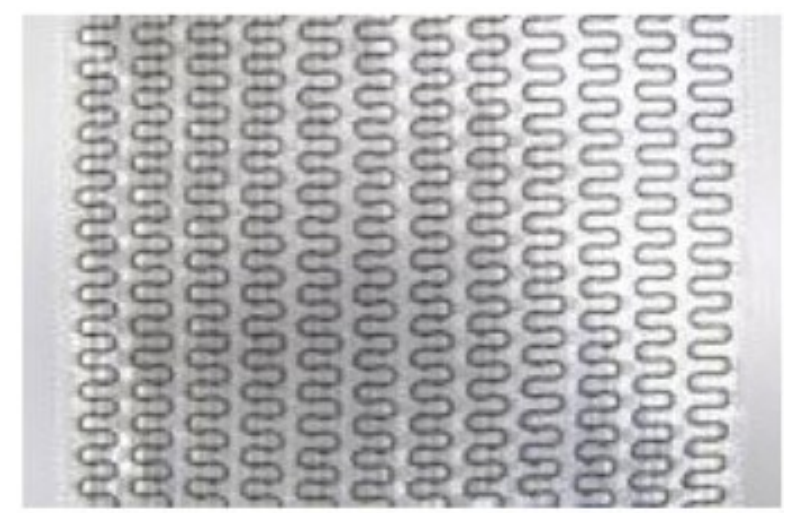

Fig. 1. Heating element 
heating temperature and applied voltage. Detailed data such as: power consumption, voltage, reached temperature are provided by the heaters manufacturers. Gerster company offers mats in which the heating elements are made of carbon roving uniformly distributed on a flexible substrate (Fig. 1). This allows for formation of tools with complex shapes made of silicone casting. The information provided by the manufacturer is also the basis for performing FEM simulations (Fig. 2) concerning temperature distribution during curing process.

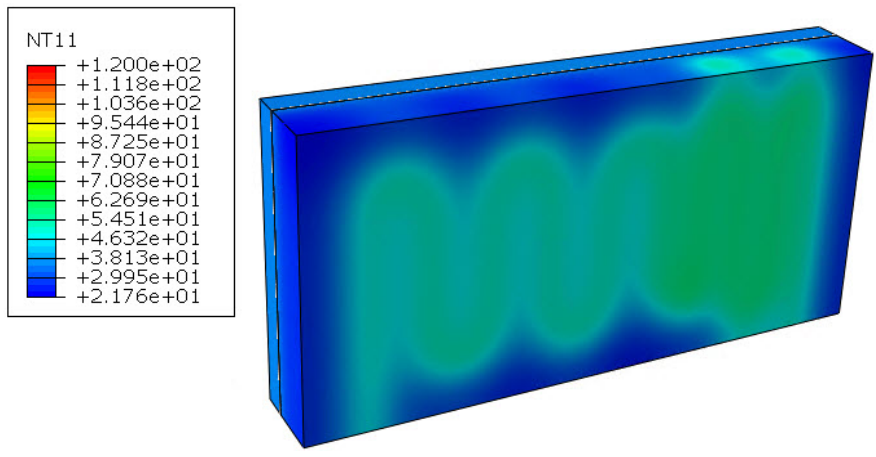

Fig. 2. FEM simulation with using of internal heating (unit in $\left[{ }^{\circ} \mathrm{C}\right]$ )

\section{Curing model formulation with application of the CDF}

Figure 3 shows 3 different geometries of analysed models during curing process. The most important parameter in the analysis is the shape of the aluminum mold, which is proposed in 3 versions. The most technological is model 1. Its advantage is the higher stiffness. However, its major disadvantage is not uniform thickness, which significantly hampers free heat transfer. The model 2 has a constant thickness of the aluminium mold equal to $10 \mathrm{~mm}$, whereas the model 3 is, to some extend, a mixture of both previous models. Thickness of the prepreg was equal to $1 \mathrm{~mm}$, whereas the silicone layer thickness $-10 \mathrm{~mm}$. The silicone in the models has to meet a double role. It serves as a grip and allows for mounting of the heater within its structure. For this purpose, the silicone layer is made as an assembly in order to obtain a continuous surface (4), see Fig. 3. The model of the aluminum mold, which is in fact formed of two halves, is also simplified by omitting of connecting flanges.
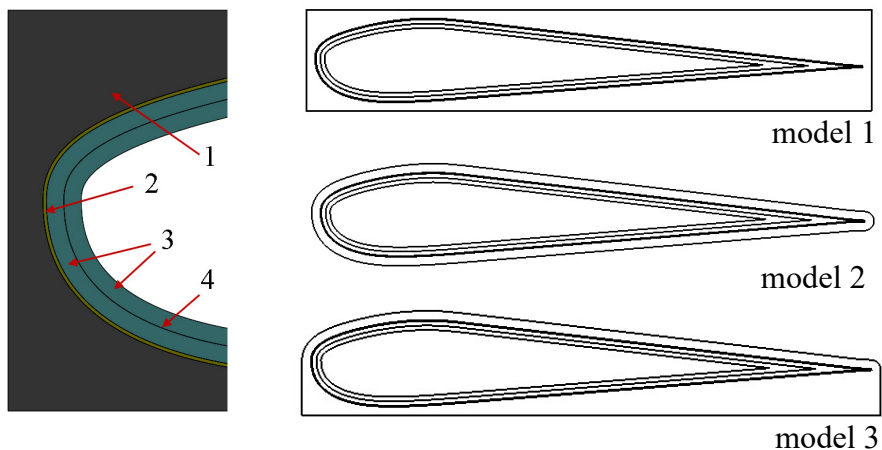

Fig. 3. Structure and analyzed mold shapes ( 1 - aluminium mold, $2-$ prepreg, 3 - silicone, 4 - interface in silicone grip)
It is not possible to use the CFD simulations for 2D models analysis, hence the thickness equal to $10 \mathrm{~mm}$ was introduced to the model to get 3D structure. Figure 4 shows the external dimensions of the model. The fluid domain must be relatively high so that there is no boundary effect of walls. Figure 5 shows the FEM mesh both for the fluid (a) and the structure (b). The global dimension for the fluid mesh was $40 \mathrm{~mm}$, however near the boundary of the structure this mesh density was condensed to the size equal to $10 \mathrm{~mm}$. Global mesh size for the mold was $5 \mathrm{~mm}$. The precise data concerning the quantity of used FEM elements are shown in Table 1.

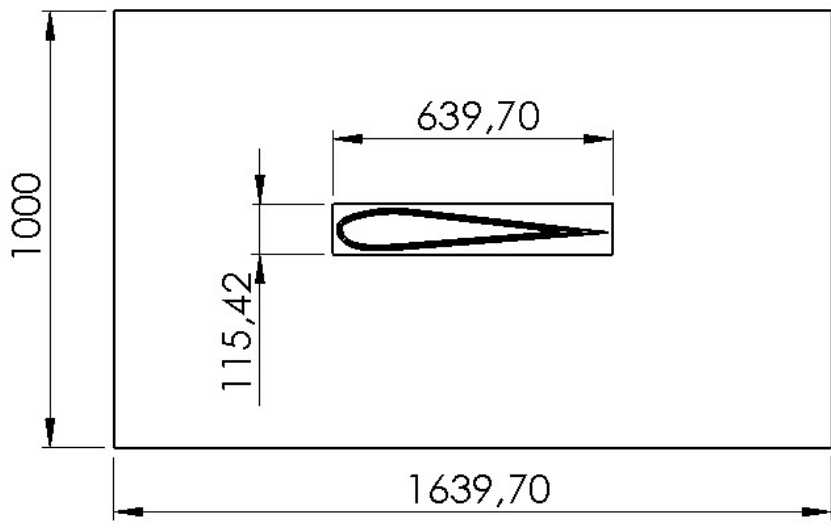

Fig. 4. External dimensions of model (unit in [mm])

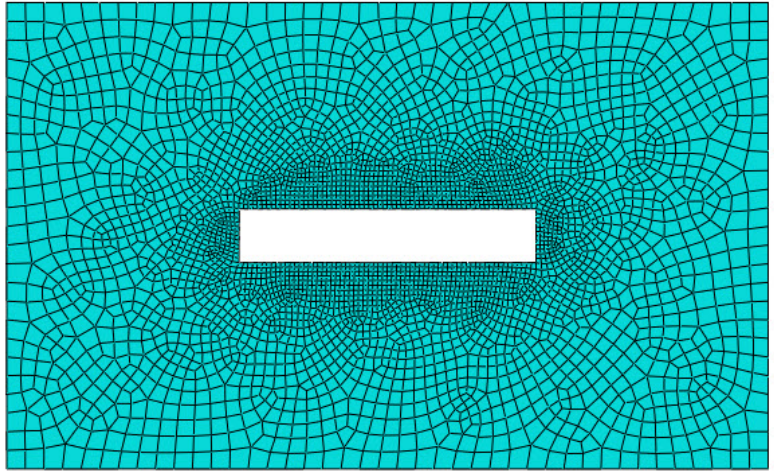

a)

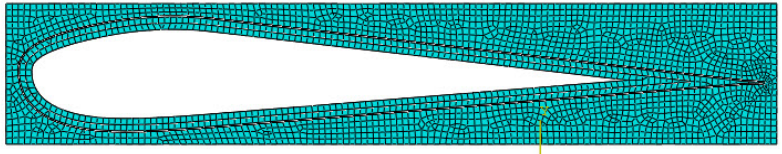

b)

Fig. 5. FEM mesh ( $\mathrm{a}$ - fluid, $\mathrm{b}$ - structure)

TABLE 1

FEM mesh

\begin{tabular}{|c|c|c|c|c|}
\hline \hline & \multicolumn{2}{|c|}{ Fluid } & \multicolumn{2}{c|}{ Structure } \\
\cline { 2 - 5 } & FC3D8 & FC3D6 & DC3D8 & DC3D6 \\
\hline Model 1 & 3691 & - & 7659 & 113 \\
\hline Mode1 2 & 3268 & 117 & 5241 & 67 \\
\hline Model 3 & 3353 & 94 & 6305 & 95 \\
\hline
\end{tabular}

In order to investigate temperature and stress distribution during curing process we studied totally 12 cases for 3 different 
geometries of the curing systems, as shown in Fig. 3. The difference in simulations consisted of the following facts:

a) boundary conditions related to the air flow direction were changed (from the leading edge and from trailing edge), i.e. 6 cases,

b) after calculation of the above cases (a) without internal heating and heat flux analysis in the prepreg layer we took decision where the silicone grip with internal heating should be placed to improve curing process -6 additional cases.

Each simulation lasted $60 \mathrm{~s}$, and the initial temperature both for structure as well as air was $20^{\circ} \mathrm{C}$. Velocity of the air was determined experimentally for the real technological stand in industry and was equal to $1.23 \mathrm{~m} / \mathrm{s}$. The inlet air temperature was $130^{\circ} \mathrm{C}$.

The conducted co-simulation concerning the heat transfer involved running of two tasks simultaneously. Therefore, necessary data related to the heat flow were collected in Table 2.

TABLE 2

Material data

\begin{tabular}{|c|c|c|c|c|}
\hline \hline & $\begin{array}{c}\text { Conductivity } \\
{[\mathrm{W} / \mathrm{mK}]}\end{array}$ & $\begin{array}{c}\text { Density } \\
{\left[\mathrm{kg} / \mathrm{m}^{3}\right]}\end{array}$ & $\begin{array}{c}\text { Specific heat } \\
{[\mathrm{J} / \mathrm{kgK}]}\end{array}$ & $\begin{array}{c}\text { Viscosity } \\
{[\mathrm{kg} / \mathrm{ms}]}\end{array}$ \\
\hline Fluid (air) & 3,34 & 0,898 & 1009 & $2,285 \mathrm{e}-5$ \\
\hline $\begin{array}{c}\text { Aluminum } \\
\text { mold }\end{array}$ & 164 & 2700 & 883 & - \\
\hline prepreg & 0,6 & 1583 & 1000 & - \\
\hline silicone & 0,2 & 1200 & 1250 & - \\
\hline
\end{tabular}

\section{The results of conjugate-simulation}

Figure 6 shows results of temperature distributions after 60 s for the 3 different geometries of the curing systems without

a)

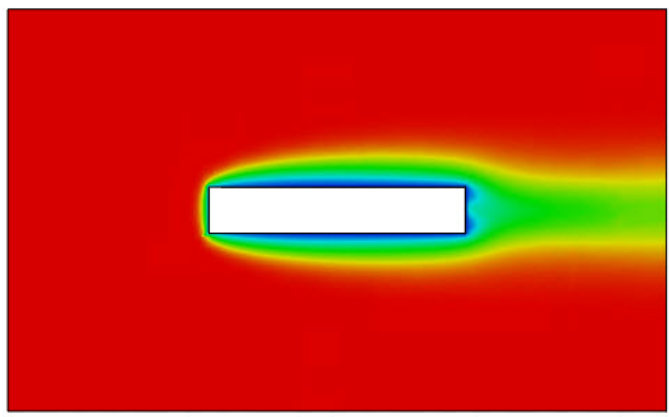

c)

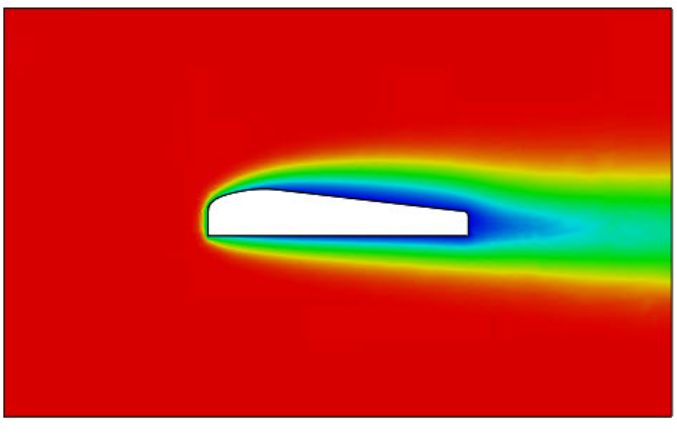

additional internal heating and for air inlet from the leading edge. Obtained nonuniform temperature fields lead to the conclusion that the temperature distribution in the prepreg layer is also affected by orientation of the mold in the autoclave or the oven. To minimize non-uniformity of the curing process, i.e. the temperature differences, it would be advantageous to apply a rotary table. However, there are difficulties with connecting wires for vacuum and sensors. Therefore, in order to determine optimal places for insertion of additional heaters, results of the numerical simulation are necessary.

The detailed analysis of temperature distribution in the structural element (Fig. 7) leads to the conclusion, that additional heaters are not required around the leading edge, but along a relatively straight section of the trailing part. For this purpose the Gerster heater with $2475 \mathrm{~W} / \mathrm{m}^{2}$ of power surface was used.

The additional heating has an effect on the increase of average temperature in the prepreg layer, see Fig. 8. In this configuration of the curing system the orientation of the mold in relation to the air flow is not so important. On the other hand, the mold shape is very important. The greatest influence was recorded for the model 1 , for which the prepreg temperature was higher approximately $21-26 \%$.

Application of additional heating allows also for reduction of the temperature difference in the prepreg layer, Fig. 9. In this case orientation of the mold is very important, e.g. for the model 1 this difference may vary from $3,7 \%$ to $8,7 \%$. However, decreasing of the temperature difference at this level is not satisfactory because the work effort of the grip implementation is disproportionate to the resulting effect. In this case, efforts should be made for greater diversity of heater power and to improve the thermal conductivity of silicone.

b)
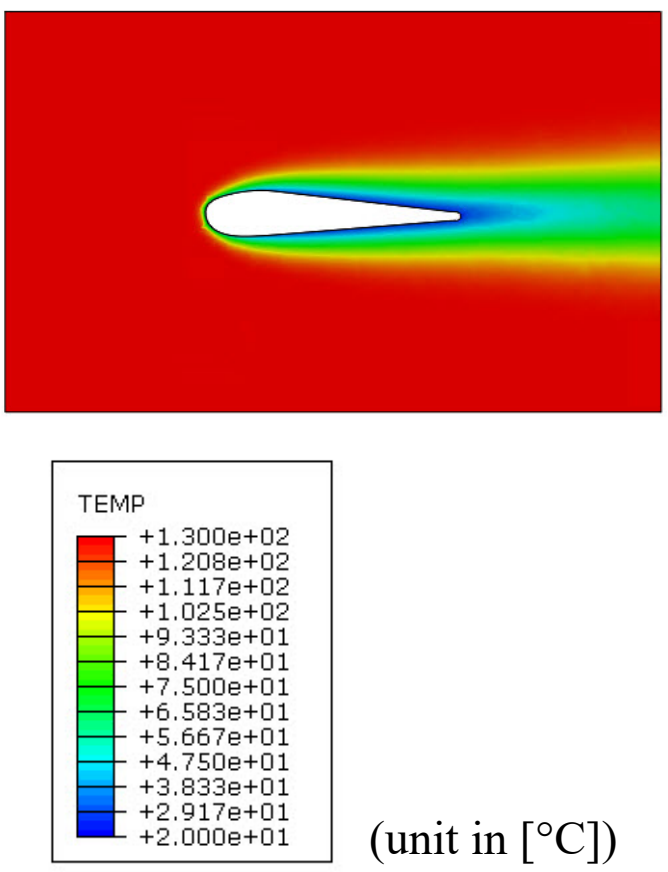

Fig. 6. Temperature distribution in air $(\mathrm{a}-$ model $1, \mathrm{~b}-\operatorname{model} 2, \mathrm{c}-$ model 3$)$ 
a)

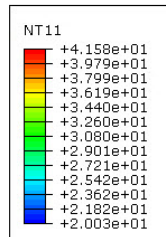

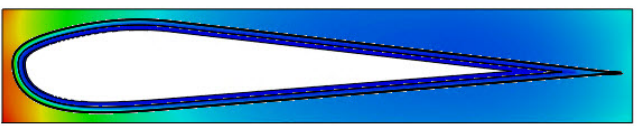

b)
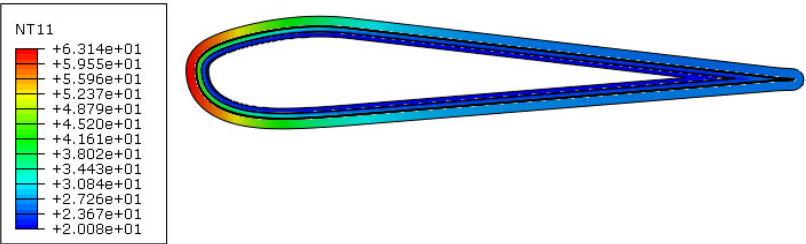

c)
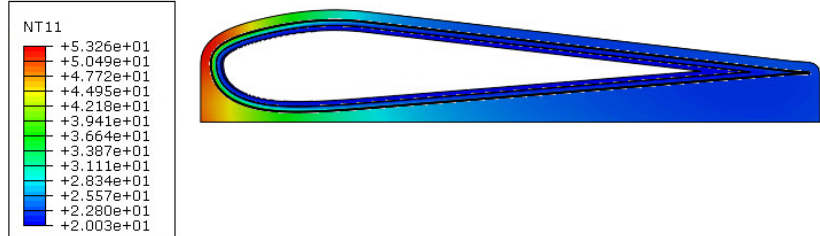

Fig. 7. Temperature distribution in structure (a-model $1, \mathrm{~b}-\operatorname{model} 2, \mathrm{c}-\operatorname{model} 3$ ), (unit in $\left[{ }^{\circ} \mathrm{C}\right]$ )

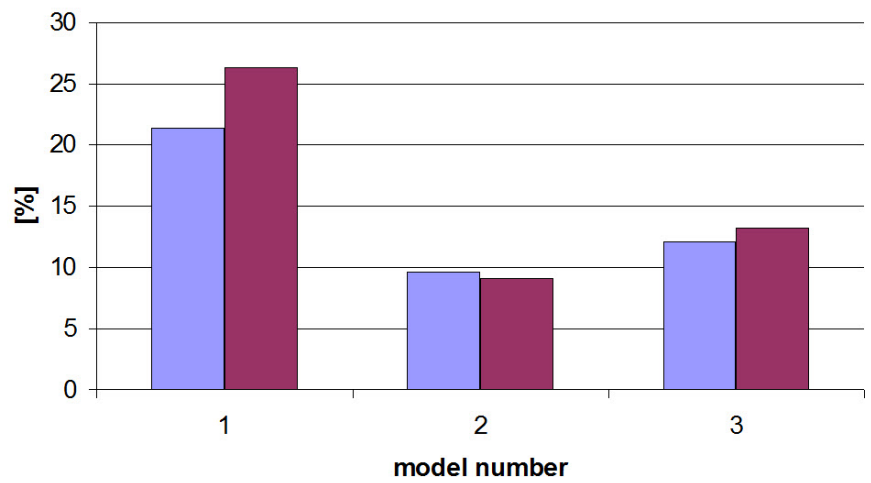

$\square$ Inlet from leading edge $\square$ Inlet from trailing edge

Fig. 8. Percentage increase of the prepreg temperature with application of the additional heaters

\section{Stress analysis of the mold}

One can notice that the CFD conjugate simulation results in the non - uniform temperature distribution in the structure. The most responsible element in the forming system as for production of structural elements with corrected dimensions is the mold. Therefore, it is important to determine stresses and displacements occurring during heating process and simultaneous interaction from silicone grip. For this purpose the temperature dependent data - taken from the paper [13] - were used for aluminum 2024 T4. They are shown in Table 3.

TABLE 3

Material data for the mold

\begin{tabular}{|c|c|c|c|c|}
\hline \hline${ }^{\circ} \mathbf{C}$ ] & $\boldsymbol{E}$ [GPa] & $\boldsymbol{R}_{\boldsymbol{e l}}$ [MPa] & $\boldsymbol{R}_{\boldsymbol{m}}$ [MPa] & $\boldsymbol{A}_{\boldsymbol{t}}$ [\%] \\
\hline 25 & 68,563 & 367,5 & 488,8 & 23,9 \\
\hline 50 & 66,879 & 367,5 & 483,0 & 23,2 \\
\hline 75 & 70,403 & 361,8 & 471,1 & 23,4 \\
\hline 100 & 65,564 & 360,3 & 466,2 & 18,4 \\
\hline 125 & 62,863 & 354,0 & 440,7 & 16,5 \\
\hline 150 & 62,082 & 348,3 & 422,5 & 17,7 \\
\hline 175 & 66,814 & 318,2 & 394,2 & 19,1 \\
\hline 200 & 46,624 & 312,9 & 383,2 & 22,2 \\
\hline
\end{tabular}

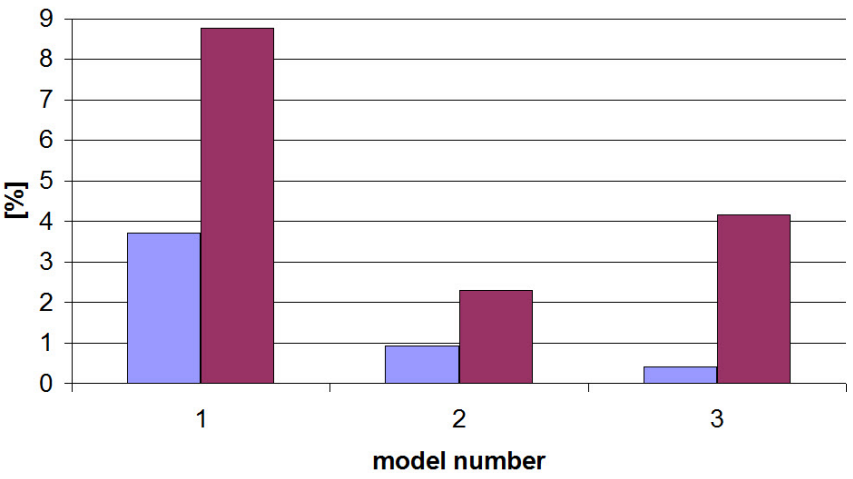

$\square$ Inlet from leading edge $\square$ Inlet from trailing edge

Fig. 9. Percentage of decrease of the temperature difference in the prepreg layer with application of the additional heaters

For stress analysis more than 8 times denser mesh was used than in the conjugate simulation. Additionally, the analyzed model was loaded by pressure inside grip with value of $0.1 \mathrm{MPa}$. The boundary displacement conditions were also assigned, assuming that the element operates in a flat strain state. The results of stress are shown for three cases (Fig. 10) without internal heating and for inlet air coming from the leading edge.

For the mold 1 the maximum values of Mises stresses concentrated on the dividing line, i.e. in the place where a flange can be mounted. Other areas of the structural element are not efforted. Different situation takes place for the mold 2 having a constant thickness equal to $10 \mathrm{~mm}$. In this case, the heat exchange is more beneficial as we get more than twice faster heating, but the mold is not stiff enough and requires additional ribs, which can not be modeled by $2 \mathrm{D}$ simulation. The presented study shows that the mold design is always a compromise between heat exchange rate and stiffness.

\section{Conclusions}

Nowadays designing process of the molds is carried out using the traditional method. Correctness of this methodology strongly depends on long-lasting designer experience. This tra- 

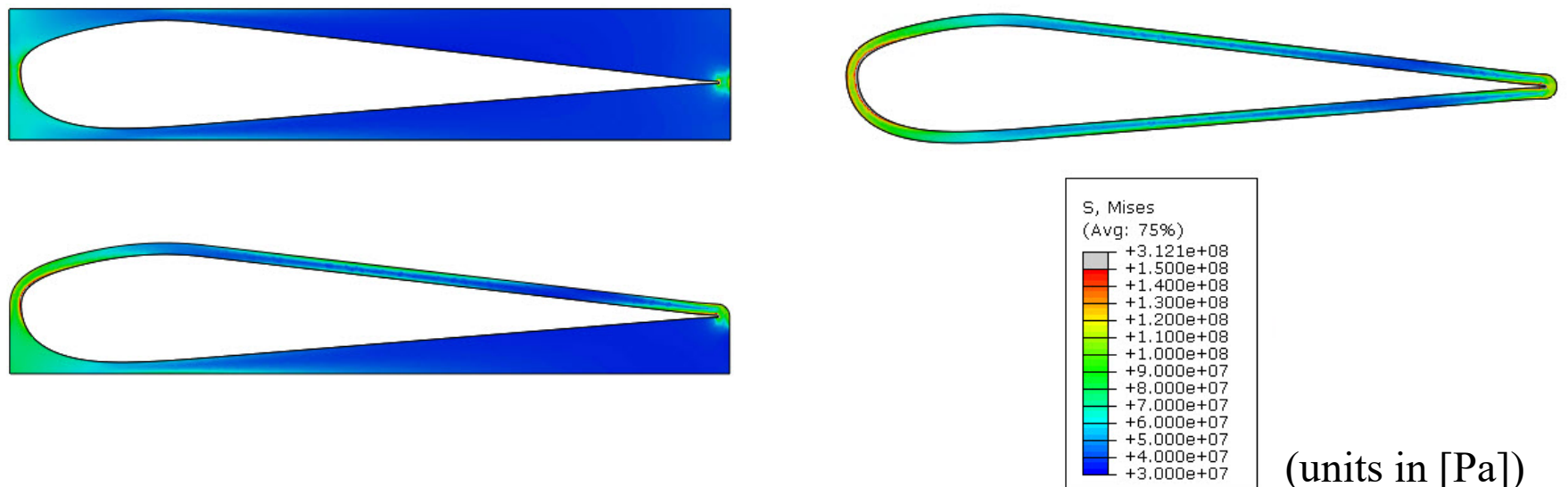

(units in $[\mathrm{Pa}]$ )

Fig. 10. Fields of Mises thermal stresses in the molds for heating without internal system

ditional approach is mostly trial and error method, which implies a high cost and time - consuming design process.

The present paper proposes improvement of the above procedure using coupled simulations to determine temperature and stress distributions in the mold. It allows for faster and more accurate mold design. Obtained results in numerical simulations lead to the following conclusions:

- due to the low thermal conductivity of silicone layer, the other materials with similar elastic properties must be sought,

- $2 \mathrm{D}$ simulations allow to roughly determine places to apply additional heating elements as well as the mold shape, but for detailed stress analysis it is necessary to perform $3 \mathrm{D}$ simulations due to the ribs consideration,

- the increase of mold external dimensions leads to increasing of the internal heating system. For the model 1 we observed increase of the average temperature about $21 \%-26 \%$, while for the model 2 which has fixed thickness $10 \mathrm{~mm}$ this change was equal to $9 \%$,

- $\quad$ percent decrease of temperature difference in the prepreg layer is dependent on the air flow in relation to the mold position in the autoclave. However, for considered cases obtained maximum decrease was equal to only $8,7 \%$. Therefore, one should endeavor to diversify power of heaters in different places of grips and to increase thermal conductivity of elastic silicone layer.

It is necessary to extend the paper to the curing model which will include also description of the existence of microcracks initiation and development of applied numerical models, e.g. $[13-21]$.

\section{Acknowledgement}

Financial support of the National Centre for Research and Development (Poland) - Project "Block Structures - Mechanical joining innovations to replace conventional fasteners in aerostructures", contract No INNOLOT/I/5/ NCBR/2013 is gratefully acknowledged.

This work was financially supported by Ministry of Science and Higher Education (Poland) within the statutory research number S/20/2016.

\section{REFERENCES}

[1] D. Walczyk, J. Kuppers, Thermal press curing of advanced thermoset composite laminate parts, Composites: Part A 43, 635-646 (2012).

[2] T. Bayerl, M. Duhovic, P. Mitschang, D. Bhattacharyya, The heating of polymer composites by electromagnetic induction A review, Composites: Part A 57, 27-40 (2014).

[3] M. Kwak, P. Robinson, A. Bismarck, R. Wise, Microwave curing of carbon-epoxy composites: Penetration depth and material characterization, Composites: Part A 75, 18-27 (2015).

[4] J.S. Weiland, M.P. Hartmann, R.M. Hinterhölzl, Cure simulation with resistively in situ heated CFRP molds: Implementation and validation, Composites: Part A 80, 171-181 (2016).

[5] R. Abdalrahman, S. Grove, A. Kyte, M.J. Rizvi, Numerical simulation and design optimisation of an integrally-heated tool for composite manufacturing, Materials and Design 64, 477-489 (2014).

[6] Y. Ding, W.K. Chiu, X.L. Liu, Numerical investigation on thermal response of oil-heated tool for manufacture of composite products, Composite Structures 47, 491-495 (1999).

[7] Y. Ding, W.K. Chiu, X.L. Liu, B. Whittingham, Modelling of thermal response of oil-heated tools due to different flow rates for the manufacture of composite structures, Composites Structures 54, 477-488 (2001).

[8] N. Athanasopoulos, G. Koutsoukis, D. Vlachos, V. Kostopoulos, Temperature uniformity analysis and development of open lightweight composite molds using carbon fibers as heating elements, Composites: Part B 50, 279-289 (2013).

[9] W.P. Benjamin, Plastic tooling techniques and applications, McGraw-Hill, (1972).

[10] T. Sadowski, P. Golewski, The influence of quantity and distribution of cooling channels of turbine elements on level of stresses in the protective layer TBC and the efficiency of cooling, Computational Materials Science 52, 293-297 (2012).

[11] T. Sadowski, P. Golewski, Multidisciplinary analysis of the operational temperature increase of turbine blades in combustion engines by application of the ceramic thermal barrier coatings (TBC), Comp. Mater. Sci. 50, 1326-1335 (2011). 
[12] T. Sadowski, P. Golewski, Detection and numerical analysis of the most efforted places in turbine blades under real working conditions, Comp. Mater. Sci. 64, 285-288 (2012).

[13] A. Lipski, S. Mroziński, The effects of temperature on the strength properties of aluminum alloy 2024-T3, Acta Mechanica et Automatica 6 3, 62-66 (2012).

[14] L. Marsavina, T. Sadowski, Fracture parameters at bi-material ceramic interfaces under bi-axial state of stress. Comp. Mater. Sci, 45, 693-697 (2009)

[15] G. Golewski, P. Golewski, T.Sadowski, Numerical modelling crack propagation under Mode II fracture in plain concretes containing siliceous fly-ash additive using XFEM method, Comput. Mat. Sci. 62, 75-78 (2012).

[16] T. Sadowski, L. Marsavina, Multiscale modelling of two-phase ceramic matrix composites Comput. Mat. Sci. 50, 1336-1346 (2011).

[17] J. Bieniaś, H. Dębski, B. Surowska, T. Sadowski, Analysis of microstructure damage in carbon/epoxy composites using FEM, Comput. Mat. Sci. 64, 168-172 (2012).

[18] V. Petrova, T. Sadowski, Theoretical modeling and analysis of thermal fracture of semi-infinite functionally graded materials with edge cracks, Meccanica 49, 2603-2615 (2014).
[19] J. Gajewski, T. Sadowski, Sensitivity analysis of crack propagation in pavement bituminous layered structures using a hybrid system integrating Artificial Neural Networks and Finite Element Method, Comput. Mat. Sci. 82, 114-117 (2014).

[17] H. Dębski, T. Sadowski, Modelling of microcracks initation and evolution along interfaces of the $\mathrm{WC} / \mathrm{Co}$ composite by the finite element method, Comput. Mat. Sci. 83, 403-411 (2014).

[18] H. Dębski, T. Sadowski, Modelling of the damage process of interfaces inside the $\mathrm{WC} / \mathrm{Co}$ composite microstructure: 2-D versus 3-D modelling technique, Comp. Struct. 159, 121-127 (2017).

[19] V.N. Burlayenko, H. Altenbach, T. Sadowski, An evaluation of displacement-based finite element models used for free vibration analysis of homogeneous and composite plates, Journal of Sound and Vibration 358, 152-175 (2015).

[20] T. Sadowski, B. Pankowski, Numerical modelling of two-phase ceramic composite response under uniaxial loading, Composite Structures 143, 388-394 (2016).

[21] T. Sadowski, Gradual degradation in two-phase ceramic composites under compression, Comput. Mat. Sci. 64, 209-211(2012). 